\title{
Serious eye injuries caused by rotating wire brushes
}

\author{
P Hassett, P E Cleary
}

Penetrating eye injuries caused by rotating wire brushes are sight threatening injuries that can be prevented and which may possibly be underreported. We report on three patients with wire brush injury who presented to this department over a 14 month period.

\section{Case reports}

CASE 1

A 69-year-old male general maintenance labourer attended eye casualty with a history of blurred vision in his left eye. He had been using an electrically driven wire brush at work when a fragment of wire broke off the brush hitting his eye. On examination, the patient had a visual acuity of 6/9 in his right eye and 6/36 in his left. He had a full thickness corneal perforation at the 6 o'clock position, a traumatic cataract, and damage to the iris sphincter. After 48 hours' observation in hospital he was discharged. Three months later he had an uncomplicated extracapsular cataract extraction with posterior chamber intraocular lens implant and achieved a visual acuity of $6 / 6$. Figure 1 shows the track of the foreign body in the lens at presentation.

\section{CASE 2}

A 45-year-old male Spanish speaking seaman was at work on board ship with a power driven wire brush when a piece of wire from the brush hit his right eye. The foreign body was removed by the ship's captain. On examination in hospital he had a visual acuity of $6 / 9$ in his right eye and $6 / 4$ in his left eye. He had a fresh full thickness corneal wound at the 7 o'clock position and an iris wound. After observation in hospital for 1 week he was discharged. The patient returned to maritime duties and did not re-attend for follow up.

\section{CASE 3}

A 44-year-old slabber attended with a history of blurred vision in his left eye 3 hours after using an electric wire brush while at work. He had noticed something entering his eye and he himself had removed a wire brush bristle from his

Department of Ophthalmology, Regional Hospital and University College, Cork, Ireland P Hassett P E Cleary Correspondence to: DrP Hassett. Accepted for publication 26 January 1994 eye. On examination he had a visual acuity of $6 / 6$ in his right eye and 6/24 in his left. Slit-lamp examination revealed a corneal perforation in the 6 o'clock position with a positive Seidel's test, an iris wound, a traumatic cataract with a track visible in the lens, and a tear of the posterior lens capsule. He underwent cataract extraction, anterior vitrectomy, and anterior chamber

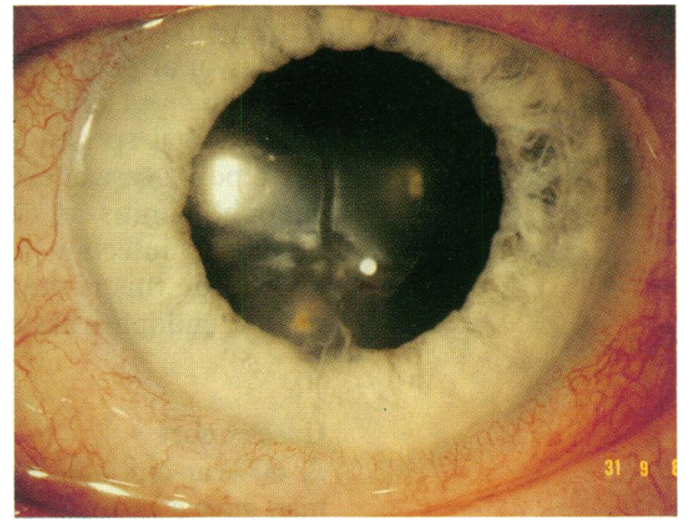

Figure 1 The damaged iris and the track of the foreign body in the lens.

intraocular lens implantation and achieved a corrected visual acuity of $6 / 9$.

\section{Comment}

Rotating wire brushes are composed of fine wire bristles projecting from one side of a metal wheel usually attached to an electric drill. These brushes are commonly used to clean surfaces, such as rusty metal, before painting. Individual bristles, which break off during use, are sharp objects and it is not surprising that they might perforate the cornea. The risk of injury may be increased if the brushes are used at high revolutions. This causes the bristles to fan out ${ }^{1}$ increasing their diameter and thus their speed. ${ }^{2}$ Consider a brush rotating at 6000 revolutions per minute. If the diameter increases from 10 to $100 \mathrm{~mm}$, the peripheral speed increases from $3 \cdot 142$ to $31 \cdot 42 \mathrm{~m} / \mathrm{s}$.

We wish to alert ophthalmologists to the potential consequences of wire brush injuries and to highlight the importance of history taking. Symptoms and signs may be minimal.

Advice on the safe use of abrasive wheels is available. ${ }^{3}$ To prevent wire brush injuries the employer must incorporate such safety information, including the use of goggles, in the work safety programme. It is recommended that safety goggles should conform to British Standard $2092 .^{4}$

1 Hoh H, Krannig H. Perforierende verletzungen der augen durch rotierende stahlbursten, Klin Monatsbl Augenheilkd 1990; 196: 166.

2 Safety in the use of abbrasive wheels. Health and Safety series booklet HS $(\mathrm{G}) 17$. London: Health and Safety Executive, booklet 1991 .

3 The Abrasive Wheel Regulations 1970 SI 1970/535. London: HMSO, 1970.

4 Specification for eye-protectors for industrial and nonindustrial uses (BS 2092). London: British Standards industrial uses
Institution, 1987. 